\title{
Determination of Gamma-aminobutyric Acid (GABA) Content in Grains and Cruciferous Vegetable Seeds
}

\author{
Fadwa Al-Taher ${ }^{1} \&$ Boris Nemzer ${ }^{1,2}$ \\ ${ }^{1}$ VDF FutureCeuticals, 2692 N. State Rte. 1-17, Momence, IL 60954, USA \\ ${ }^{2}$ University of Illinois in Urbana-Champaign, Urbana, IL 60014, USA \\ Correspondence: Fadwa Al-Taher, VDF FutureCeuticals, 2692 N. State Rt. 1-17, Momence, IL 60954, USA. Tel: \\ 1-815-507-1421. E-mail: Fadwa.Al-Taher@futureceuticals.com
}

\author{
Received: August 27, $2019 \quad$ Accepted: October 10, $2019 \quad$ Online Published: October 15, 2019 \\ doi:10.5539/jfr.v8n6p49 \\ URL: https://doi.org/10.5539/jfr.v8n6p49
}

\begin{abstract}
Gamma aminobutyric acid (GABA) has great physiological functions, mainly as a major inhibitory neurotransmitter in the brain, which makes it important for the development of functional foods. This study detected GABA in grains and cruciferous vegetable seeds by using HPLC after pre-column on-line derivatization with diode array detection (DAD) and fluorescence detection (FLD). The limit of quantitation was 2.94 and 2.86 $\mu \mathrm{g} / \mathrm{mL}$ with DAD and FLD, respectively. GABA recoveries ranged from 98.8 to $111.2 \%$ on both detectors. Intra and inter-day precision showed relative standard deviations, generally, less than $10 \%$ for both DAD and FLD. GABA was determined in different grains (flaxseeds, white quinoa seeds, and buckwheat) and cruciferous vegetable seeds (broccoli, kale, daikon radish, mustard, cabbage, and brussels sprouts). Organic broccoli seeds contained the highest amount and mustard seeds the least amount of GABA in the Brassica family with none being detected in organic white quinoa and flaxseeds. A statistically significant difference $(\mathrm{p}<0.05)$ exists between the various lots of the broccoli seeds. GABA is important as a natural source in functional foods.
\end{abstract}

Keywords: gamma-aminobutyric acid (GABA), cruciferous vegetable seeds, grains, germination, sonication, pre-column derivatization

\section{Introduction}

Gamma aminobutyric acid (GABA) is a four-carbon non-proteinogenic amino acid and a major inhibitory neurotransmitter in the brain. It has several physiological roles, mainly in the human central nervous system (Watanbe, Maemura, Kanbara, Tamayama \& Hayasaki, 2002). Most recently, GABA as a bioactive compound has become popular for its functional and health effects because it has been recognized to improve brain function (Watanbe et al., 2002), lower blood pressure (Inoue et al., 2003), reduce insomnia (Plante, Jensen, Schoerning \& Winkelman, 2012), induce relaxation and diminish anxiety (Abdou, Higashiguchi, Horie, Hatta, \& Yokogoshi, 2006) and inhibit impulsivity (Silveri et al., 2013). It is also believed to help prevent diabetes (Taneera et al., 2012; Braun et al., 2010). Moreover, GABA can delay and/or prevent the spread of cancer cells and stimulate apoptosis in cancer cells. Additionally, it is shown to suppress tumors as well (Diana, Quílez, \& Rafecas, 2014).

GABA is synthesized primarily from glutamate by the enzyme glutamate decarboxylase (GAD) with pyridoxal phosphate (the active form of vitamin B6) as a cofactor (Watanbe et al., 2002). GABA exists naturally in small quantities in many plant sources: vegetables (spinach, potatoes, cabbage, asparagus, broccoli and tomatoes), fruits (apples and grapes), and cereals (barley and maize). A high amount of GABA is found mainly in fermented products such as fermented dairy products, soy sauces and cheeses. Although the human body can generate its own GABA, it is sometimes hindered by a lack of estrogen, zinc or vitamins, or by a high amount of salicylic acid and food additives in the diet (Diana, Quílez, \& Rafecas, 2014). With aging, ability to produce GABA in the cerebral cortex weakens (Leventhal, Wang, $\mathrm{Pu}, \mathrm{Zhou}, \& \mathrm{Ma}, 2003$ ). Therefore, it is worthwhile to consider dietary or nutritional supplements for GABA.

To promote and maintain the health of the consumers, it is pertinent to discover new natural food sources of GABA and development of functional foods. Particularly, grains and seeds will potentially be used as raw ingredients in nutritional GABA supplements and as raw materials for sprouts. Beans, rice, and wheat seeds have been used for germination studies to increase the content of GABA (Yang, Guo, \& Gu, 2013; Ding et al., 2018a; 
Ding et al., 2018b). GABA content for fava beans sprouted for five days under hypoxia was 2.21-fold higher than that of the control (Yang, Guo, \& Gu, 2013). Hayat et al. (2015) determined controlled brown rice samples to be $47-65 \mathrm{mg} / \mathrm{kg}, 115-935 \mathrm{mg} / \mathrm{kg}$ for germinated and $1032-1089 \mathrm{mg} / \mathrm{kg}$ for fermented samples. Ding et al. (2018a) noticed that GABA in red rice was $2.91 \mathrm{mg} / 100 \mathrm{~g}$ and increased after germination for $72 \mathrm{~h}$ and was 15.4 times higher than the un-germinated rice. GABA content in the wheat non-sprouting sample contained $14.68 \pm$ $0.43 \mathrm{mg} / 100 \mathrm{~g}$, which after a $72 \mathrm{~h}$ germination increased by 339\% (Ding et al., 2018b). GABA content in grains and cruciferous vegetable seeds, which can be used as health promoting food ingredients such as flaxseeds, quinoa, barley and broccoli seeds, has not been established.

GABA content for germination of grains experiments has been tested primarily by using HPLC on a reversed phase column, C-8 or C18 after pre-column online derivatization with o-phthaldialdehyde (OPA) (Hayat et al., 2015; Ding et al., 2018a) or with addition of dansyl chloride to the sample (Ding et al., 2018b) and detection by an ultraviolet visible (UV-Vis) detector. Zhao et al. (2011) analyzed GABA in Chinese teas with HPLC-FLD using OPA for pre-column online derivatization. Ding et al. (2016) tested GABA in ungerminated and germinated dehulled rice under normoxic and hypoxic conditions by GC-MS using bismethylsilane trifluoracetamide (BSTFA) to derivatize samples. However, these analytical methods have not been used to determine GABA in grains and cruciferous vegetable seeds.

The objective of this study was to determine the amount of gamma aminobutyric acid (GABA) in grains and cruciferous vegetable seeds using high performance liquid chromatography with diode array detector (DAD) and a fluorescence detector (FLD). GABA content was also assessed in various lots of broccoli seeds.

\section{Materials and Methods}

\subsection{Chemicals and Reagents}

Sodium phosphate dibasic, $\left(\mathrm{Na}^{2} \mathrm{HPO} 4\right.$; purity $\geqslant 99 \%$ ), sodium tetraborate decahydrate $\left(\mathrm{Na}^{2} \mathrm{~B} 4 \mathrm{O} 7.10 \mathrm{H}_{2} \mathrm{O}\right.$; purity $\geqslant 99.5 \%)$, sodium azide $\left(\mathrm{NaN}_{3}\right.$; purity $\left.\geqslant 99.5 \%\right)$, gamma-aminobutyric acid (GABA; $>99 \%$ purity) and norvaline (internal standard; > 98\% purity) were purchased from Millipore Sigma (St. Louis, MO, USA). All chemicals and reagents used were of analytical grade. Phosphoric acid, ACS grade and 36.5-38\% $\mathrm{HCl}$, ACS grade were obtained from VWR International (Radnor, PA, USA). Acetonitrile and methanol, both HPLC grade were acquired from EMD Millipore Corp. (Darmstadt, Germany). The solutions were prepared with ultra-pure water (Milli-Q system; Millipore, Bedford, MA, USA). Borate buffer (0.4 N, pH 10.2) and o-phthaldialdehyde (OPA) reagent $(10 \mathrm{mg} / \mathrm{mL})$ used for derivatization were purchased from Agilent Technologies (Santa Clara, CA, USA).

\subsection{Material and Sample Preparation}

A variety of grains and cruciferous vegetable seeds were collected from suppliers of VDF FutureCeuticals in Momence, IL. Caudill Seed Company (Louisville, KY, USA) supplied the organic (A) and conventional (A-E) broccoli seeds, organic buckwheat seeds, mustard seeds and organic daikon radish seeds. Organic white quinoa seeds were acquired from Colorexa (Deerfield Beach, FL, USA). Organic kale was purchased from Johnny's Seeds (Winslow, ME, USA). Organic broccoli seeds (B) and organic flaxseeds were obtained from Organic Quality Food (Spring, TX, USA). The collected grains and cruciferous vegetable seeds were then ground to a fine powder with an Economical Analytical Mill (IKA A11 basic, Germany) and stored at room temperature until they were used for extraction.

\subsection{Extraction of GABA}

Approximately $100 \pm 10.0 \mathrm{mg}$ ground grains and cruciferous vegetable seeds were extracted using $5 \mathrm{~mL}$ of Milli-Q water at room temperature $\left(\sim 23^{\circ} \mathrm{C}\right)$. Norvaline, added to a final concentration of $50 \mu \mathrm{g} / \mathrm{mL}$ was used as an internal standard. Each sample was shaken on a wrist shaker for $30 \mathrm{~min}$, and sonicated in an ultrasonic bath for another $30 \mathrm{~min}$. The solution was centrifuged at $8000 \mathrm{rpm}$ for $10 \mathrm{~min}$ at room temperature $\left(\sim 23^{\circ} \mathrm{C}\right)$. The supernatant was filtered through a $0.45-\mu \mathrm{m}$ nylon syringe filter into a $2 \mathrm{~mL}$ HPLC autosampler vial and the filtrate was used to determine the GABA content.

\subsection{Analysis}

Separation of GABA from the grains and cruciferous vegetable seeds was performed on an Agilent 1100 HPLC system (Agilent Technologies, Santa Clara, CA, USA) with an ultraviolet- visible diode array detector (DAD) $(338 \mathrm{~nm})$ and a fluorescence detector (FLD) (Excitation $230 \mathrm{~nm}$ and Emission $450 \mathrm{~nm}$ ). The separation was achieved using a Zorbax Eclipse AAA C18 column $(4.6$ x $150 \mathrm{~mm}, 3.5 \mu \mathrm{m})$ from Agilent Technologies. Analysis was prepared according to Agilent's Application Note for amino acids (Henderson \& Brooks, 2010). 
Linearity of the method for GABA was determined to be in the concentration range of $4-120 \mu \mathrm{g} / \mathrm{mL}$. The coefficient of determination (R2) was 0.99979 for the DAD and 0.99904 for the FLD indicating the goodness of the fit of the data to the regression line. The RSDs of the intraday (repeatability) results for GABA in organic white quinoa seeds were $6.0 \%$ and $5.5 \%$ for the $5 \mu \mathrm{g} / \mathrm{mL}$ level and $0.51 \%$ and $0.49 \%$ for $50 \mu \mathrm{g} / \mathrm{mL}$, with the DAD and FLD, respectively. The RSDs of the interday (intermediate precision) results for GABA were 10.8\% and $6.4 \%$ for the $5 \mu \mathrm{g} / \mathrm{mL}$ level, $3.8 \%$ and $3.6 \%$ for $50 \mu \mathrm{g} / \mathrm{mL}$, and $1.4 \%$ and $3.1 \%$ for $100 \mu \mathrm{g} / \mathrm{mL}$, with the DAD and FLD, respectively.

Limit of detection (LOD) was calculated as $3 \mathrm{~s}$ and limit of quantitation (LOQ) as 10s, where $\mathrm{s}$ is the standard deviation. LOD for GABA was 0.881 and $0.857 \mu \mathrm{g} / \mathrm{mL}$ with DAD and FLD, respectively, whereas LOQ was found to be 2.94 and $2.86 \mu \mathrm{g} / \mathrm{mL}$ with DAD and FLD, respectively.

Trueness was evaluated by determining the average recoveries (\%) of GABA in flaxseed and quinoa blank samples. No blank broccoli samples were found to perform this study. A broccoli sample containing GABA $(1278 \mu \mathrm{g} / \mathrm{g}$ and $1331 \mu \mathrm{g} / \mathrm{g}$ as detected by DAD and FLD, respectively) was therefore chosen for the recovery study. Average Recoveries (\%) of GABA in select grains/cruciferous vegetable seeds are shown in Table 1. Recoveries ranged from 100.0 to $110.5 \%$ with the DAD and 98.8 to $111.2 \%$ with the FLD detector, which established the accuracy of the method.

Table 1. Average GABA recoveries $(\%) \pm \%$ RSD in select grains and cruciferous vegetable seeds $(\mathrm{n}=4)$

\begin{tabular}{|c|c|c|c|c|c|c|}
\hline Grains/Seeds & Flaxseeds & & Quinoa & & Broccoli & \\
\hline $\begin{array}{l}\text { Concentration } \\
\text { spiked }(\mu \mathrm{g} / \mathrm{mL})\end{array}$ & $\begin{array}{l}\text { DAD \% Rec } \\
\pm \% \text { RSD }\end{array}$ & $\begin{array}{l}\text { FLD \% Rec } \\
\pm \% \text { RSD }\end{array}$ & $\begin{array}{l}\text { DAD \% Rec } \\
\pm \% \text { RSD }\end{array}$ & $\begin{array}{l}\text { FLD \% Rec } \\
\pm \% \text { RSD }\end{array}$ & $\begin{array}{l}\text { DAD \% Rec } \\
\pm \% \text { RSD }\end{array}$ & $\begin{array}{l}\text { FLD \% Rec } \\
\pm \% \text { RSD }\end{array}$ \\
\hline 5 & $107.9 \pm 2.1$ & $100.5 \pm 5.7$ & $101.1 \pm 3.0$ & $105.5 \pm 2.7$ & $104.8 \pm 1.4$ & $104.1 \pm 3.9$ \\
\hline 50 & $100.0 \pm 4.6$ & $99.4 \pm 0.54$ & $101.0 \pm 6.9$ & $104.8 \pm 6.8$ & $102.5 \pm 1.1$ & $98.8 \pm 0.65$ \\
\hline 100 & $101.8 \pm 1.2$ & $106.8 \pm 1.0$ & $106.7 \pm 0.73$ & $111.2 \pm 1.1$ & $110.5 \pm 9.1$ & $102.5 \pm 0.78$ \\
\hline
\end{tabular}

\subsection{Statistical Analysis}

GABA identification and quantitation data generation for grains and cruciferous vegetable seeds was performed using Agilent Technology's Chemstation Openlab CDS Rev. C.01.05 (Santa Clara, CA, USA). Data analysis was performed to calculate the means, standard deviations and relative standard deviations using Microsoft Excel 365 ProPlus version 1903. Statistical analysis was performed with one-way analysis of variance (ANOVA) with significance set at $\mathrm{p}$ values of $<0.05$ using SigmaPlot 14.0 (Systat Software; San Jose, CA, USA).

\section{Results and Discussion}

\subsection{Extraction of GABA in Seeds}

Zhao et al. (2011) extracted GABA from tea in hot water $\left(85^{\circ} \mathrm{C}\right)$ for 2 hours. In this study, we observed that extraction of GABA with hot water did not work. Preliminary investigation was performed using ground organic broccoli seeds to determine the effectiveness of water extraction only (shaken for $30 \mathrm{~min}$ ) versus water extraction (shaken for $30 \mathrm{~min}$ ) and then sonication $(30 \mathrm{~min})$ at room temperature. Results showed that with sonication the level of GABA increased $32.2 \%$ and $34.7 \%$, $(\mathrm{n}=4)$ with a significant difference $(\mathrm{p}<0.05)$ when detected by the DAD and FLD, respectively.

Ultrasound increases extraction by additionally disrupting the plant tissue (Mason, Paniwnyk, \& Lorimer, 1996). The increase in GABA content with sonication has been previously demonstrated. Yang, Gao, Yang \& Chen (2015) found that ultrasound treatment increases the germination rate, sprout length, and GABA content of soybean sprouts. Ding et al. (2018a) showed that GABA content in red rice significantly increased after germination for $72 \mathrm{~h}$ and further increased at different stages during germination upon ultrasound treatment. In another study, Ding et al. (2018b) demonstrated that the GABA content in the ultrasound-treated soft white wheat was $30.7 \%$ higher than that without ultrasound treatment. Therefore, to optimize the extraction of GABA, water and sonication were used for the analyses of grains and cruciferous vegetable seeds. GABA was extracted from grains and cruciferous vegetable seeds with water at room temperature $\left(\sim 23^{\circ} \mathrm{C}\right)$ for $30 \mathrm{~min}$. and sonication for $30 \mathrm{~min}$.

\subsection{Analysis of GABA in Grains and Cruciferous Vegetable Seeds}

Select grains and seeds belonging to the genus Brassica were screened for GABA. Table 2 lists the mean GABA concentrations $(n=4)$ and standard deviations (stdev) found in each of select grains and cruciferous vegetable seeds with mostly similar results obtained when identified using both detectors, DAD and FLD. It can be 
observed that all of the Brassica vegetable seeds contained GABA ranging from $41.38 \pm 2.67 \mathrm{mg} / 100 \mathrm{~g}$ to 116.6 $\pm 6.48 \mathrm{mg} / 100 \mathrm{~g}$ with DAD and $41.10 \pm 2.46 \mathrm{mg} / 100 \mathrm{~g}$ to $118.91 \pm 4.06 \mathrm{mg} / 100 \mathrm{~g}$ with FLD. Results showed that organic broccoli seeds contained the highest amount and mustard seeds the least amount of GABA in the Brassica family with none being detected in organic white quinoa and flaxseeds.

Table 2. Mean GABA concentration $(\mathrm{mg} / 100 \mathrm{~g} \pm \mathrm{stdev})$ in grains and cruciferous vegetable seeds $(\mathrm{n}=4)$

\begin{tabular}{lll}
\hline Grains/Cruciferous Seeds & DAD & FLD \\
\cline { 2 - 3 } & $\mathbf{m g} / \mathbf{1 0 0 g} \pm \mathbf{\text { stdev }}$ & $\mathbf{m g} / \mathbf{1 0 0 g} \pm \mathbf{s t d e v}$ \\
\hline Conventional Broccoli seeds & $104.1 \pm 2.50$ & $108.9 \pm 3.47$ \\
Organic Broccoli seeds & $116.6 \pm 6.48$ & $118.91 \pm 4.06$ \\
Organic White Quinoa seeds & $\mathrm{ND}$ & $\mathrm{ND}$ \\
Organic Buckwheat seeds & $10.58 \pm 0.751$ & $10.20 \pm 0.686$ \\
Organic Flaxseeds & $\mathrm{ND}$ & $\mathrm{ND}$ \\
Organic Kale & $57.39 \pm 4.01$ & $62.62 \pm 3.79$ \\
Mustard seeds & $41.38 \pm 2.67$ & $41.10 \pm 2.46$ \\
Organic Daikon Radish & $57.10 \pm 4.75$ & $54.16 \pm 4.60$ \\
Organic Cabbage Dutch (green) seeds & $83.93 \pm 3.92$ & $94.13 \pm 4.48$ \\
Red Express Organic Cabbage (purple-red) seeds & $70.86 \pm 5.49$ & $83.88 \pm 7.20$ \\
Brussel Sprouts seeds & $62.75 \pm 13.5$ & $70.61 \pm 13.18$ \\
\hline
\end{tabular}

*ND-denotes not detected

Various lots of broccoli seeds, organic and conventional were assessed for GABA. Lot-to-lot variability of broccoli seeds was examined for GABA $(n=4)$. Figure 1 depicts GABA content in the broccoli seeds lots analyzed. GABA concentrations ranged from $93.9 \pm 13.4 \mathrm{mg} / 100 \mathrm{~g}$ to $131.9 \pm 3.17 \mathrm{mg} / 100 \mathrm{~g}$ on the DAD and $96.03 \pm 19.5 \mathrm{mg} / 100 \mathrm{~g}$ to $129.7 \pm 6.21 \mathrm{mg} / 100 \mathrm{~g}$ on the FLD.

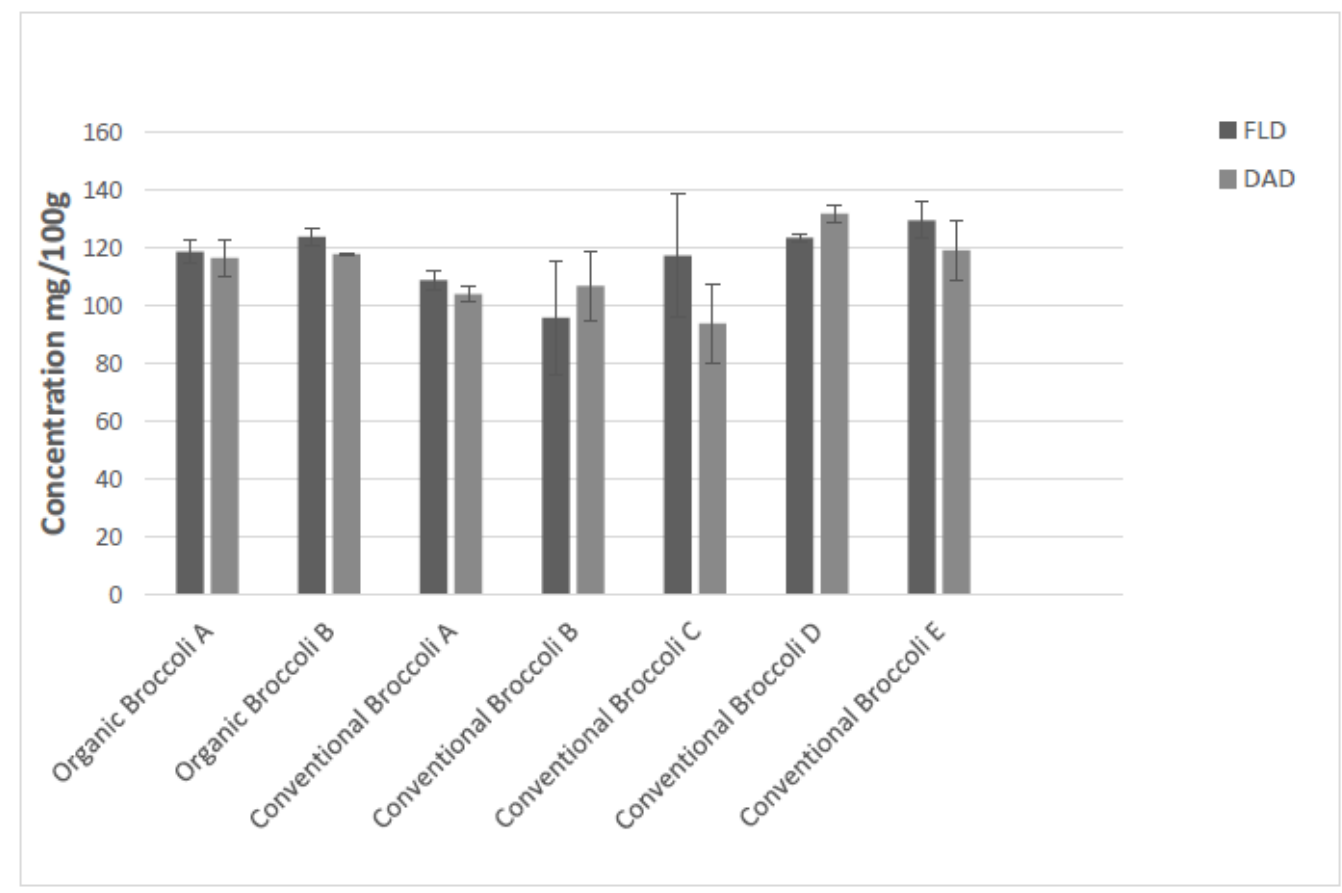

Figure 1. GABA content in various lots of organic and conventional broccoli samples

Although obtained from different suppliers, GABA content was similar in the two organic broccoli seeds and showed no significant difference $(\mathrm{p}>0.05)$ with the DAD and $(\mathrm{p}>0.05)$ with the FLD. Overall, there is a statistically significant difference for GABA results in conventional broccoli seeds observed by DAD $(\mathrm{p}<0.05)$. Conventional Broccoli $\mathrm{C}$ is significantly different from Organic Broccoli A, Organic Broccoli B, Conventional Broccoli D and Conventional Broccoli E as detected on the DAD ( $p<0.05)$. Conventional Broccoli D is also 
significantly different from Conventional Broccoli A and Conventional Broccoli B with the DAD $(\mathrm{p}<0.05)$.

In general, there is also a statistically significant difference $(p<0.05)$ for GABA results in broccoli seeds obtained with FLD. Conventional Broccoli B is significantly different $(p<0.05)$ from Organic Broccoli B, Conventional Broccoli D and Conventional Broccoli E with the FLD.

While broccoli samples were obtained mainly from the same supplier, a statistically significant difference does exist between the various lots of the broccoli seeds. There was not enough data for organic broccoli seeds to compare with the conventional broccoli seeds to draw a conclusion on the relative GABA content. However, it is evident from Figure 1 that broccoli seeds do contain a high GABA content.

\section{Conclusion}

This is the first time that results have been reported of GABA content in different grains (flaxseeds, white quinoa seeds, and buckwheat) and cruciferous vegetable seeds (broccoli, kale, daikon radish, mustard, cabbage, and brussels sprouts). The levels of GABA determined in this study indicate that broccoli seeds, or their short time germinated sprouts should be useful as a natural source of GABA in human diet.

\section{References}

Abdou, A. M., Higashiguchi, S., Horie, K., Hatta, H., \& Yokogoshi, H. (2006). Relaxation and immunity enhancement effects of $\gamma$-Aminobutyric acid (GABA) administration in humans. BioFactors, 26, 201-208. https://doi.org/10.1002/biof.5520260305

Braun, M., Ramracheya, R., Bengtsson, M., Clark, A., Walker, J. N., Johnson, P. R., \& Rorsman, P. (2010). $\gamma$-Aminobutyric acid (GABA) is an autocrine excitatory transmitter in human pancreatic $\beta$-cells. Diabetes, 59, 1694-1701. https://doi.org/10.2337/db09-0797

Diana, M., Quílez, J., \& Rafecas, M. (2014). Gamma-aminobutyric acid as a bioactive compound in foods: a review. Journal of Functional Foods, 10, 407-420. https://doi.org/10.1016/j.jff.2014.07.004

Ding, J., Ulanov, A. V., Dong, M., Yang, T., Nemzer, B. V., Xiong, S., \& Feng, H. (2018a). Enhancement of gamma-aminobutyric acid (GABA) and other health-related metabolites in germinated red rice (Oryza sativa L.) by ultrasonication. Ultrasonics Sonochemistry, 40, 791-797.

http://dx.doi.org/10.1016/j.ultsonch.2017.08.029

Ding, J., Hou, G. G., Nemzer, B. V., Xiong, S., Dubat, A., \& Feng, H. (2018b). Effects of controlled germination on selected physiochemical and functional properties of whole-wheat flour and enhanced $\gamma$-aminobutyric acid accumulation by ultrasonication. Food Chemistry, 243, 214-221.

http://dx.doi.org/10.1016/j.foodchem.2017.09.128

Ding, J., Yang, T., Feng, H., Dong, M., Slavin, M., Xiong, S., \& Zhao, S. (2016). Enhancing contents of $\gamma$-Aminobutyric acid (GABA) and other micronutrients in dehulled rice during germination under normoxic and hypoxic conditions. Journal of Agricultural and Food Chemistry, 64, 1094-1102. http://dx.doi.org/10.1021/acs.jafc.5b04859

Hayat, A., Jahangir, T. M., Khuhawar, M. Y., Alamgir, M., Hussain, Z., Haq, F. U., \& Musharraf, S. G. (2015). HPLC determination of gamma amino butyric acid (GABA) and some biogenic amines (BAs) in controlled, germinated, and fermented brown rice by pre-column derivatization. Journal of Cereal Science, 64, 56-62. http://dx.doi.org/10.1016/j.jcs.2015.04.014

Henderson, J. W., \& Brooks, A. (2010). Improved amino acid methods using Agilent Zorbax Eclipse Plus C18 columns for a variety of Agilent LC instrumentation and separation goals (Application Note 5990-4547EN). Retrieved from https://www.agilent.com/cs/library/applications/5990-4547EN.pdf

Inoue, K., Shirai, T., Ochiai, H., Kasao, M., Hayakawa, K., Kimura, M., \& Sansawa, H. (2003). Blood-pressure-lowering effect of a novel fermented milk containing $\gamma$-aminobutyric acid (GABA) in mild hypertensives. European Journal of Clinical Nutrition, 57, 490-495. https://doi.org/10.1038/sj.ejcn.1601555

Leventhal, A. G., Wang, Y., Pu, M., Zhou, Y., \& Ma, Y. (2003). GABA and its agonists improved visual cortical function in senescent monkeys. Science, 300, 812-815. https://doi.org/10.1126/science.1082874

Mason, T. J., Paniwnyk, L., \& Lorimer, J. P. (1996). The uses of ultrasound in food technology. Ultrasonics Sonochemistry, 3, S253-S260. https://doi.org/10.1016/S1350-4177(96)00034-X

Plante, D. T., Jensen, J. E., Schoerning, L., \& Winkelman, J. W. (2012). Reduced $\gamma$-Aminobutyric acid in occipital and anterior cingulate cortices in primary insomnia: a link to major depressive disorder? Neuropsychopharmacology, 37, 1548-1557. https://doi.org/10.1038/npp.2012.4 
Silveri, M. M., Sneider, J. T., Crowley, D. J., Covell, M. J., Acharya, D., Rosso, I. M., \& Jensen, J. E. (2013). Frontal lobe $\gamma$-Aminobutryic acid levels during adolescence: associations with impulsivity and response isolation. Biological Psychiatry, 74, 296-304. https://doi.org/10.1016/j.biopsych.2013.01.033

Taneera, J., Jin, Z., Jin, Y., Muhammed, S. J., Zhang, E., Lang, S., Salehi, A., Korsgren, O., Renström, E., Groop, L., \& Birnir, B. (2012). $\gamma$-Aminobutyric acid (GABA) signaling in human pancreatic islets is altered in type 2 diabetes. Diabetologia, 55, 1985-1994. https://doi.org/10.1007/s00125-012-2548-7

Watanbe, M., Maemura, K., Kanbara, K., Tamayama, T., \& Hayasaki, H. (2002). GABA and GABA receptors in the central nervous system and other organs. International Review of Cytology, 213, 1-47. https://doi.org/10.1016/S0074-7696(02)13011-7

Yang, H., Gao, J., Yang, A., \& Chen, H. (2015). The ultrasound-treated soybean seeds improve edibility and nutritional quality of soybean sprouts. Food Research International, 77, 704-710. http://dx.doi.org/10.1016/j.foodres.2015.01.011

Yang, R., Guo, Q., \& Gu, Z. (2013). GABA shunt and polyamine degradation pathway on $\gamma$-aminobutyric acid accumulation in germinating fava bean (Vicia faba L.) under hypoxia. Food Chemistry, 136, 152-159. http://dx.doi.org/10.1016/j.foodchem.2012.08.008

Zhao, M., Ma, Y., Wei, Z., Yuan, W., Li, Y., Zhang, C., Xue, X., \& Zhou, H. (2011). Determination and comparison of $\gamma$-Aminobutyric acid (GABA) content in Pu-erh and other types of Chinese tea. Journal of Agricultural and Food Chemistry, 59, 3641-3648. http://dx.doi.org/10.1021/jf104601v

\section{Copyrights}

Copyright for this article is retained by the author(s), with first publication rights granted to the journal.

This is an open-access article distributed under the terms and conditions of the Creative Commons Attribution license (http://creativecommons.org/licenses/by/4.0/). 